\title{
A Mutated Yeast Strain with Enhanced Ethanol Production Ef- ficiency and Stress Tolerance
}

\author{
Naghmeh Hemmati ${ }^{1 *}$, David A. Lightfoot ${ }^{1,2}$, and Ahmed Fakhoury ${ }^{3}$
}

1 Department of Plant Soil and Agricultural Systems, Southern Illinois University at Carbondale, Carbondale, IL 62901-4415, USA; ${ }^{2}$ Department of Biochemistry and Molecular Biology, Southern Illinois University at Carbondale, Carbondale, IL 62901 USA; $^{3}$ Department of Plant Soil and Agricultural Systems, Southern Illinois University at Carbondale, Carbondale, IL 62901 USA

Received: July 15, 2011 / Accepted: May 6, 2012

\begin{abstract}
One of the strategies to improve and optimize bio-ethanol production from new feed stocks is to develop new strains of Saccharomyces cerevisiae with tolerance to stresses. The main objectives here were to; generate $S$. cerevisiae mutants tolerant to high ethanol concentrations; test for their ability to ferment maize starch; and partially characterize the mutations responsible for the new phenotypes. A combination of mutagenesis, selection and cross-stress protection methods were used. EMS (ethyl methanesulfonate) was used to mutagenize one S. cerevisiae strain. The mutagenized yeast strain was exposed to high concentrations of ethanol and tolerant mutants were isolated. Mutants showed improved ethanol yield (0.02-0.03 $\mathrm{g} / \mathrm{g}$ of maize) and fermentation efficiency (3-5\%). Finally, AFLP (Amplified Fragment Length Polymorphism) was performed to identify polymorphisms in the mutants that might underlie the strains ethanol tolerance. The best performing mutant isolate had four altered gene transcripts encoding; an arginine uptake and canavanine resistance protein (CAN1); mitochondrial membrane proteins (SLS1); a putative membrane glycoprotein (VTH1); and cytochrome C oxidase (COX6; EC 1.9.3.1) among about 1,000 tested. It was concluded these mutations might underlie the improved ethanol production efficiency and stress tolerance.

Keywords: AFLP, Mutagenesis, Polymorphism, SNPs, Ethanol tolerance, CAN1, SLS1, VTH1, COX6, Ethanol yield, Fermentation Efficiency.
\end{abstract}

\footnotetext{
* Corresponding author: naghmeh@siu.edu
}

\section{Introduction}

Modern civilization has been greatly dependent on the oxidation of fossil fuel reserves over the past 150 years for energy production (Hambourger et al., 2009; Stephenson et al., 2011). Fossil fuel reserves are limited and their current oxidation rate is a major global and environmental concern, with complex and severe impacts on the climate of the planet (DECC, 2009; Stephenson et al., 2011).

Several factors have contributed to a revival of interest in bio-fuels, both in the United States and worldwide (Bothast et al., 1999; Jeffries and Jin, 2004; Fargione et al., 2008). These include; a steep increase in the price of crude oil and crude oilbased products, an increase in the awareness of the detrimental effects of burning fossil fuels, release of greenhouse gases; a renewed political awareness of the need for decreasing the reliance of the economy on foreign oil and the availability of land set aside from food crop production ideal for biofuel crops (Bothast et al., 1999; Jeffries and Jin, 2004).

Saccharomyces cerevisiae has been broadly used for fuel ethanol production due to its ability to produce high concentration of ethanol from simple sugars. Ethanol counts as a toxin for yeast cells and tolerance to it is closely related to ethanol productivity which is a major factor in industrial ethanol production (Jones, 1989). Improving and increasing understanding of the impact of ethanol toxicity on yeast cells will assist enhancing yeast ethanol tolerance and higher ethanol production (Demain, 2009; Stanley, 2010).

Earlier studies showed that the acquired tolerance to formerly lethal stress levels has been linked to the activation of specific 
stress response mechanisms during pre-exposure to the sub-lethal stress (Plesset et al., 1982; Sanchez and Lindquist, 1990; Coote et al., 1991). The effects of pre-exposure to stress conditions have been studied in ethanol stress (Vriesekoop and Pamment, 2005) and other stress conditions such as osmotic (Trollmo et al., 1988; Varela et al., 1992) and oxidative stresses (Davies et al., 1995). Stanley et al. (2010) proposed that pretreated yeast cultures showed a $70 \%$ reduction in the stress adaptation period when exposed to higher ethanol concentrations. Therefore, the isolation of stress resistant strains should include a pretreatment phase. However, improving the efficiency of ethanol production in engineered strains is not trivial. Selection for small scale batch culture growth and the numbers of background mutations are the major issues that have been hard to overcome. The main objectives of the research reported here were to; generate $S$. cerevisiae mutants with improved toleranance to high concentrations of ethanol; assess the ability of the mutants to produce bio-ethanol in larger scale cultures; and to partially characterize the mutations.

\section{Materials and Methods}

\section{Strains}

The yeast strain (NCYC-1681 Brewing strain) that was developed for fermentation was chosen for this experiment. The strain was; round-oval in colony shape; cream in color; had a shiny surface; and showed a smooth texture on agar. Cell viability was retained during fermentation to final ethanol concentrations of $15 \%(v / v)$. The strain was obtained from the National Collection of Yeast Cultures, Institute of Food Research, Norwich Research Park, Norwich, United Kingdom, NR4, 7UA.

\section{Media}

The complete growth medium for S. cerevisiae consisted of YPD liquid and solid medium (YPD Broth, Fisher). Yeast storage stock solutions were prepared by adding $15 \%(\mathrm{v} / \mathrm{v})$ glycerol to complete growth medium of yeast after 24 hours and were stored at $-80^{\circ} \mathrm{C}$.

\section{Mutagenesis and Screening for Survival Rate}

A modified version of Burke et al. (2000) was used. Briefly, the cells were incubated at room temperature in $200 \mu \mathrm{l}$ sterilized distilled water containing $8 \%(\mathrm{w} / \mathrm{v}$ ) EMS for 5-20 min with constant vortexing. The optimum lethal dose (LD) of each EMS concentration was calculated. The aim was to identify $70 \%$ to $80 \%$ lethality and was obtained by plating and incubating an appropriate dilution of cells at $30^{\circ} \mathrm{C}$ overnight. The growing colonies were isolated after 24 hours.

\section{Selection of Ethanol-Tolerant Mutants}

Previous researchers have demonstrated that pre-exposure of yeast to a sub-lethal amount of stressing agent such as ethanol or heat can stimulate molecular responses resulting in resis- tance to higher levels of the same stress condition compared to control cells, cells without pre-exposure (Plesset et al., 1982; Sanchez and Lindquist, 1990; Coote et al., 1991). In the current research study, pre-treatment to stress condition (ethanol stress) and selection were performed after the mutagenesis step. Briefly, about $0.1 \mathrm{ml}$ of the cell suspension $(2 \times 108 \mathrm{cell} / \mathrm{ml})$ was added to $20 \mathrm{ml}$ YPD liquid and cultivated at $30^{\circ} \mathrm{C}$ overnight. The cells were exposed to gradual additions of absolute ethanol $(99.9 \%$ with $0.1 \%(\mathrm{v} / \mathrm{v})$ methanol) to cultures. Concentrations were raised from $5 \%$ to $35 \%-40 \%(\mathrm{v} / \mathrm{v}$ ) within 5 days (additions were $5 \%$ ethanol for the first day; $5 \%$ for the second day; $10 \%$ for the third day, $10 \%$ for the fourth day; and $5 \%$ $10 \%$ for the fifth day). Positive controls (with $0 \%$ ethanol) were cultured under identical conditions. After the fifth day the cells were pelleted, washed and suspended in $2 \mathrm{ml}$ sterilized distilled water. The resulting suspensions were plated on YPD-agar and cultured at $30^{\circ} \mathrm{C}$ overnight for mutant selection. This procedure was repeated more than 20 times and each time there were 3 replications. The growing colonies showed that the mutant strain was able to tolerate ethanol up to $40 \%(v / v)$.

\section{Testing Fermentation Abilities}

The mutants (two mutants) and the parent strain were sent to National Corn to Ethanol Research Center (NCERC) in Edwardsville, IL to test for their fermentation ability (NCERC, 2007). The process was divided into three steps; preparation of yeast strains, liquefaction of starch substrate and fermentation. The ethanol yields and fermentation efficiencies for yeast strains (one control and two mutants) were calculated from the ethanol concentrations measured by HPLC after 64.5 hours of fermentation. The statistical significance of the differences between samples was evaluated using analysis of variance (ANOVA).

\section{DNA Extraction}

Genomic DNA was obtained following Chung, (1996). DNA quality was assessed by spectrophotometer (Spectronic, Madison, WI) by calculating the $\mathrm{A} 260 / \mathrm{A} 280 \mathrm{~nm}$ ratios and the $\mathrm{A} 260$ $\mathrm{nm}$ values were used to determine DNA concentrations. The DNA was stored at $-20^{\circ} \mathrm{C}$ for the subsequent experiments.

\section{AFLP (Amplified Fragment Length Polymorphism) and Transforma- tion}

AFLP analysis was carried out using the AFLP Microorganism Primer Kit (Invitrogen, Carlsbad, CA). Polyacrylamide gel electrophoresis (PAGE) was divided to five major steps; preparation of glass plates; assembling and pouring the gel; electrophoresis for $2 \mathrm{~h}$ at 200V; fixing and silver staining gels; and extracting the bands with altered intensities in mutants or control strains from the gel.

PCR was performed using band DNA as a template with the appropriate selective AFLP primers. Amplified bands were separated and purified by agarose gel electrophoresis. QIAquick Gel Extraction Kit (Qiagen, Hilden, Germany) was used to extract the bands from the agarose gel. pGEM®-T or pGEM®-T 
Easy Vectors Kit from Promega (Madison, WI) was used for ligation. Transformations were made into E.coli as follows. The tubes containing the ligation reactions were centrifuged to collect contents at the bottom of the tubes. Just $1 \mu$ l of the ligation reaction was added to $10 \mu \mathrm{l}$ of thawed JM109 High Efficiency Competent CellsTM. The reaction was mixed gently. The tubes were placed on ice for 20 minutes. The cells were placed on a heat plate for $45-50$ seconds at exactly $42^{\circ} \mathrm{C}$ and immediately after that tubes were returned to ice for 2 minutes. About 900 $\mu \mathrm{l}$ of $L B$ medium was added to each tube and was incubated at $37^{\circ} \mathrm{C}$ for 1.5 hours. About $100 \mu \mathrm{l}$ of each transformation reaction was plated on LB agar $(0.625 \%(\mathrm{w} / \mathrm{v}))$ with $100 \mu \mathrm{gg} /$ $\mathrm{ml}$ ampicillin, $100 \mu \mathrm{g} / \mathrm{ml} \mathrm{X-gal} \mathrm{and} \mathrm{IPTG}(80 \mu \mathrm{g} / \mathrm{ml})$. The plates were incubated at $37^{\circ} \mathrm{C}$ overnight. White and blue colonies were identified after incubation.

\section{Plasmid DNA Purification and Sequencing}

Two or three white colonies from each sample were cultured in separate tubes containing $5 \mathrm{ml} \mathrm{LB}$ medium and incubated in a shaker and incubator (150 rpm) at $37{ }^{\circ} \mathrm{C}$ overnight. Wizard $\mathbb{R}$ Plus SV Minipreps DNA Purification System Kit (Promega) was used for isolation and purification of plasmid DNA. A PCR reaction was performed on the plasmid DNA and DNA quality was assessed and the size of each fragment was estimated after agarose gel electrophoresis. DNA sequencing was carried out at the lowa State University DNA Facility.

The DNA sequences were analyzed by VecScreen (vector screen), BLAST (basic local alignment search tool) at NCBI (National Center for Biotechnology Information) and SGD (Saccharomyces Genome Database). SNPs (single nucleotide polymorphisms) in the sequences were recognized and recorded.

\section{Results and Discussion}

\section{Fermentation}

Two mutants were isolated that could grow when ethanol concentrations were $35-40 \%(\mathrm{v} / \mathrm{v})$ in media. In contrast the parent strain did not grow at concentrations above $15 \%$. Medium scale fermentation data indicated mutants had better ethanol yields (Figure 1) and fermentation efficiency than the parent strain (Figure 2).

\section{Polymorphic AFLP band isolation}

Overall, 10 bands were identified polymorphic from the primer pairs tested (Figure 3). The primer pairs generated about 10 discernible bands. Of those, 8 were dominant bands in the mutant. They were labeled as $M 1$ to M8. Only two dominant polymorphic bands were found in control and absent from the mutant. They were labeled as C1-C2. The estimated size of the DNA fragments that showed polymorphism varied from 250 to $495 \mathrm{bp}$.

From the 10 DNA fragments identified, $8\left(C 2, M_{2}, M_{3}, M_{4}, M_{5}\right.$, $M_{6}, M_{7}$ and $M_{8}$ ) were successfully isolated. After transformation, minipreps and PCR steps, 6 DNA fragments were successfully

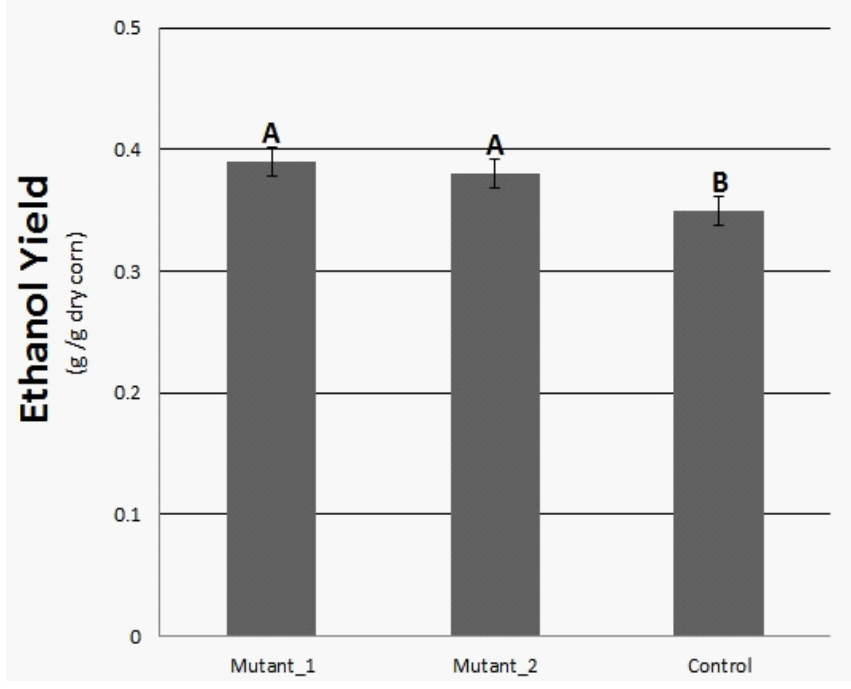

Figure 1. Ethanol yield for all yeast strains that were tested, the parental control and the two mutants. The error bars represent one standard deviation of three independent replicate fermentations. The ethanol yields were calculated for each yeast strain from the ethanol concentrations measured by HPLC after 64.5 hours of fermentation. The statistical significance of the differences between hybrids was evaluated using analysis of variance (ANOVA). Statistically significant differences were detected among the ethanol yields for the yeast strains that were tested $(P=1.79 \times 10-5)$, where $P$ is the probability that the ethanol yield for all yeast strains is the same. Strains with same letter were not statistically significantly different from each other.

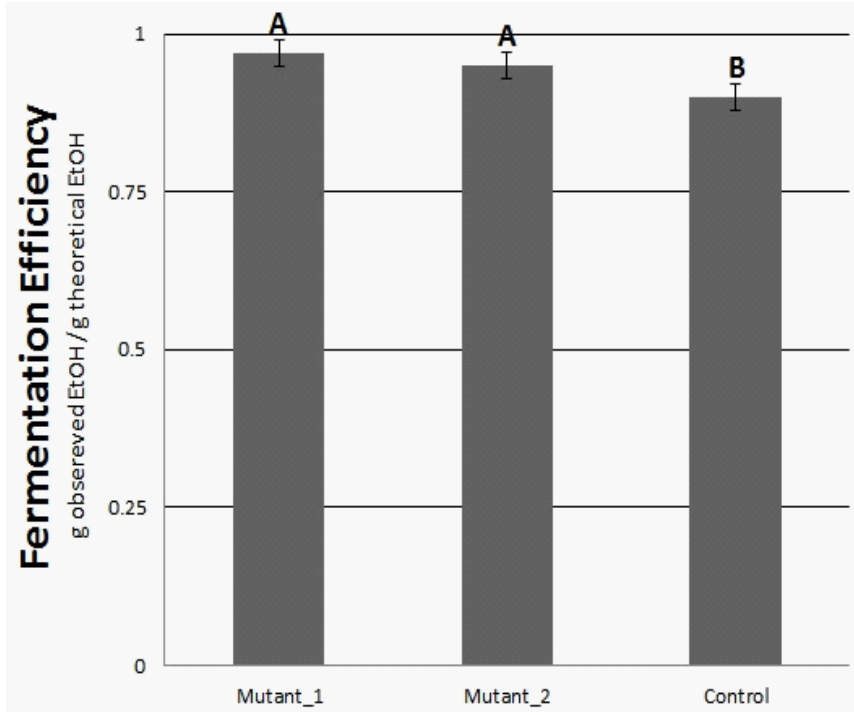

Figure 2. Fermentation efficiency for all yeast strains that were tested, the parental control and the two mutants. The error bars represent one standard deviation of three independent replicate fermentations. The fermentation efficiency was calculated for each yeast strain from the ethanol concentrations measured by HPLC after 64.5 hours of fermentation. The statistical significance of the differences between hybrids was evaluated using analysis of variance (ANOVA). Statistically significant differences were detected among the ethanol yields for the yeast strains that were tested $(P=1.79 \times 10-5)$, where $P$ is the probability that the ethanol yield for all yeast strains is the same. Strains with same letter were not statistically significantly different from each other. 
Table 1. List of geneic non-synonymous mutations detected by DNA sequence of bands showing polymorphisms by AFLP of genomic DNA (Figure 3).

\begin{tabular}{lllll}
\hline $\begin{array}{l}\text { Gene } \\
\text { Name }\end{array}$ & Gene ID & Segment & SNP & $\begin{array}{l}\text { Amino } \\
\text { Acid }\end{array}$ \\
\hline CAN1 & 856646 & $\mathrm{C}_{2}$ & C453T & A117A \\
CAN1 & 856646 & $\mathrm{C}_{2}$ & T627G & S176A \\
CAN1 & 856646 & $M_{4}, M_{5}$ & G566T & V155V \\
CAN1 & 856646 & $M_{5}$ & T637A & I178N \\
SLS1 & 850830 & $M_{2}$ & G645A & K98K \\
SLS1 & 850830 & $M_{2}$ & G675C & L108L \\
VTH1 & 854634 & $M_{3}$ & Insertion361ATA & A102D,T \\
VTH1 & 854634 & $M_{3}$ & T369A & N104K \\
VTH1 & 854634 & $M_{3}$ & T372C & Y105Y \\
VTH1 & 854634 & $M_{3}$ & T374A & F106Y \\
VTH1 & 854634 & $M_{3}$ & A445G & N130D \\
COX6 & 856448 & $M_{7}$ & T732C & A94A \\
\hline
\end{tabular}

isolated and DNA sequence analyzed (C2 464 bp; $M_{2} 468$ bp; $M_{3} 450$ bp; M4 446 bp; M5 457 bp and M7 327 bp).

\section{Gene identification}

BLAST searches indicated that three fragments, $C 2, M_{4}$, and $M_{5}$, showed high similarity (C2 98\%; M4 98\%; M5 99\%) to the CAN1 gene,YEL063C (Supplementary Figure 1, Section A). CAN1 gene family members encode membrane proteins with about 590 amino acids that function as arginine permeases (SGD \# CAN1/YEL063C ). The CAN1 gene is required for arginine uptake by yeast cells and canavanine resistance by selective exclusion (Rak et al., 2007).

Two SNPs were found between the mutant and the wild type allele in the alignment between $\mathrm{C} 2$ and CAN1 gene (Table 1; Supplementary Figure 1, section C). Both SNPs, were in coding regions (Supplementary Figure 1, section B). One of the SNPs changed the amino acid sequence and produced nonsynonymous amino acid but the other one did not change the amino acid sequence and produced synonymous change in amino acid sequence (Annotation Table).

One SNP was found between the mutant and the wild type allele in the alignment between M4 insert and the expected CAN1 gene sequence (Supplementary Figure 1, section E). The only SNP was in coding regions (Supplementary Figure 1, section D). This SNP did not change the amino acid sequence and produced synonymous amino acid (Annotation Table).

Two SNPs were found between the mutant and the wild type allele in the alignment between $M_{5}$ insert and the expected CAN1 gene sequence (Supplementary Figure 1, section $G$ ). Both SNPs, were in coding regions (Supplementary Figure 1, section F). One of the SNPs changed the amino acid sequence and produced nonsynonymous amino acid but the other one did not change the amino acid sequence and produced synonymous change in amino acid sequence (Annotation Table).

The transportation systems for many amino acids are proton symports that an amino acid molecule enters the cell along with a proton $\left(\mathrm{H}^{+}\right)$. The $\mathrm{H}^{+}$ion entry to the cell reduces cellular $\mathrm{pH}$. The cell preventive reaction from acidification of cytoplasm, maintaining cell $\mathrm{pH}$ and secondary transport mechanisms, is exporting the proton into the outside medium by a membrane bound ATPase that acts as a transporter which actively pumps hydrogen ions. During the fermentation for ethanol production, amino acid transport in yeast cells was strongly inhibited by the significant amounts of ethanol. The reason that yeast cells prevent the uptake of amino acids along with protons would be related to stopping too many protons from entering the cell (Dharmadhikari, 2007, Aguilera et al., 2006, Monteiro and Sa'Correia, 1998; Ogawa et al., 2000; Rosa and Sa'-Correia, 1991).

Many research studies presented that membrane structure and function are the predominant target of ethanol stress. Exposure of yeast to ethanol results in increased membrane fluidity and consequential decrease in membrane integrity (Mishra and Prasad, 1989). Teixeira et al. (2009) demonstrated a detailed physiological and molecular study that illustrates changes in plasma membrane organization and function of yeast cells as a response to ethanol stress. The results agreed with the previous researches (Meaden et al., 1999; Rosa and Sa'-Correia, 1991; Salgueiro et al., 1988).

The desired phenotype, tolerance to high concentration of ethanol, might be related to mutations that have been observed in CAN1 gene. The polymorphism observed in the CAN1 gene may have resulted in molecular modifications (via EMS mutagenesis and pre-treatment to stress condition) that improved the uptake of arginine (amino acid) in the presence of high concentration of ethanol. The higher tolerance to ethanol in mutants might be related to improved amino acid up-take during fermentation.

$M_{2}$ fragment showed high similarity (99\%) to the SLS1 gene. Two SNPs were found between the mutant and the wild type allele in the alignment between the $M_{2}$ insert and SLS1 gene sequence (Table 1; Supplementary Figure 2, section C). Both SNPs were in coding regions (Supplementary Figure 2, section B). Both SNPs did not change amino acid sequence and resulted in synonymous amino acid (Annotation Table). The SLS1 gene is located on Crick strand of chromosome XII and encoded for mitochondrial membrane proteins with 643 amino acids, (Supplementary Figure 2, Section A). SLS1 gene is one of the required factors for assembly of respiratory-chain enzyme complexes. It also coordinates in expression of mitochondria-encoded genes and delivery of mRNA to membrane-bound translation machinery (SGD, 2008). The finding here is further evidence that the major targets of ethanol are membrane structure and function as described by earlier researches (Mishra and Prasad, 1989; Teixeira et al., 2009). Benitez and Codon (2003) also indicated that the destructive effect sites of ethanol activity in yeast are the plasma membrane, hydrophobic proteins of the cell, mitochondrial membranes, nuclear membrane, vacuolar membrane, endoplasmic reticulum, and hydrophobic proteins in the cytoplasm. Previous research showed Respiratory Deficient (RD) mutants had lower growth rate, fermentation rate and respiration rate than aerobically growing wild strain of yeast. RD mutants were anaerobically grown cells which did not have active mitochondria and oxidative metabolism. The results illustrated the functional mitochondria was necessary for a greater tolerance to ethanol in yeast cells. It was suggested that the fac- 
tor responsible for the improvement in ethanol tolerance was not respiratory metabolism itself but majorly was more about the differences in cellular components, membrane lipids and the physiology derived the ability of yeast cell to respire (Aguilera and Benitez, 1985; Van Uden, 1989).

Teixeira et al (2009) indicated that the 30 common mitochondrial genes were also yeast resistant genes to high concentrations of ethanol, suggesting mitochondrial functions were essential for ethanol tolerance even in the presence of glucose. These results were also reconfirmed the previous findings that ethanol tolerance depends on the stability of the mitochondrial genome (Jimenez and Benitez, 1988).

The desired phenotype, tolerance to high concentration of ethanol, might be related to mutations that have been observed in SLS1 gene. The polymorphism observed in the SLS1 gene may have resulted in molecular modifications (via EMS mutagenesis and pre-treatment to stress condition) that improved cellular components, membrane lipid compositions and modified membrane fluidity which are required for higher ethanol tolerance during anaerobic fermentation (Aguilera and Benitez, 1985; Van Uden, 1989; Teixeira et al., 2009).

The $M_{3}$ Sequence Showed High Similarity (96\%) to the VTH1 Gene, YIL173W. Four mutations and indel, three nucleotide insertions, were detected between the mutant and the wild type allele in the alignment between the $M_{3}$ fragment and the VTH1 gene sequence (Table 1; Supplementary Figure 3, section $C$ ). All four SNPs and indel, three nucleotide insertions, were in coding region (Supplementary Figure 3 , section $B$ ). Three of four SNPs changed the amino acid sequence and produced nonsynonymous amino acid. One of them did not change the amino acid sequence and produces a synonymous amino acid. The three nucleotide insertions, indel, changed the amino sequence and produced two nonsynonymous amino acids (Annotation Table ). The VTHI gene is located on Watson strand of chromosome IX (Supplementary Figure 3, Section A). It encodes for putative membrane glycoprotein with 1,549 amino acids. And it may function in vacuolar protein sorting (SGD, 2008).

Ethanol can disrupt the vacuolar membrane and release the proteases into cytoplasm which results in inactivation of intracellular enzymes (Van Uden, 1989). Teixeira et al. (2009) demonstrated that many of the genes required for ethanol tolerance in yeast are related to intracellular trafficking, including vacuolar protein targeting, endosome transport, and transport mediated by the endosomal sorting complexes. They described that the target point to overcome stress imposed by lipophilic agents such as ethanol, are the membrane transporters. Ethanol stress alters vacuole morphology from segregated structures to a single, large organelle (Meaden et al., 1999). Chandler et al. (2004) found that gene expression profiles of ethanol stressed cells are different in the later stages of ethanol stress. And the major induced genes (YRO2, ALD4, ARG4, LAP4, PCL5, SSU1, YGL1 17W) at this stage are associated with energy utilization, general stress response and vacuole function. Fujita et al. (2006) found hundred and thirty-seven mutants as ethanol sensitive mutant with a considerable number of vacuole function-related genes being necessary for growth in the presence of ethanol stress. The outcomes of different research studies of genome-

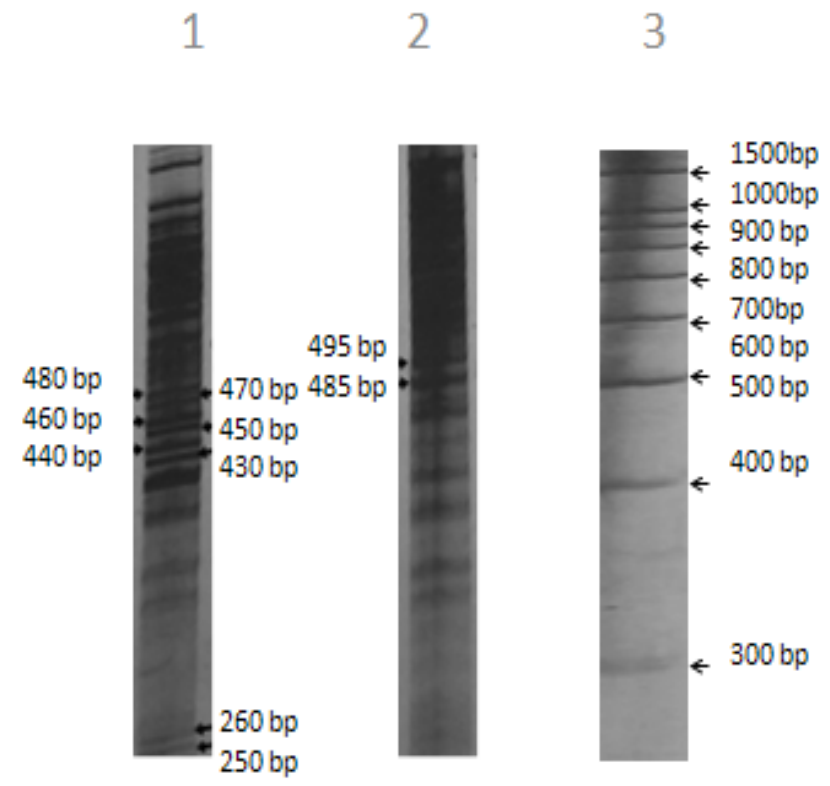

Figure 3. AFLP fingerprints of genomic DNA between mutant 1 (lane 1) and the wild type strain (lane2). Amplification products are shown from primers EcoRl/AC and Msel/G. There was $20 \mu \mathrm{g}$ DNA per lane. The $100 \mathrm{bp}$ Promega DNA ladder was used as a size standard (lane 3). Arrowed are 10 polymorphic bands detected and eluted from this gel for DNA sequencing.

wide screens for ethanol tolerance commonly agree on genes associated with vacuole function and amino acid biosynthesis as important factors for ethanol tolerance (Stanley et al., 2010).

The desired phenotype, tolerance to high concentration of ethanol, might be related to mutations that have been observed in VTH1 gene. The polymorphism observed in the VTH1 gene may have resulted in molecular modification (via EMS mutagenesis and pre-treatment to stress condition) that had positive effects on vacuole morphology, alteration in vacuole-based functions such as maintaining intracellular $\mathrm{pH}$ and ion homoeostasis, vacuole protein sorting and transportation in the cell (Stanley et al. 2010).

The $M_{7}$ sequence showed high similarity (99\%) to COX6 gene (YHR051W). One mutation was observed in COX6 gene. The SNP was found between the mutant gene and the wild type allele in the alignment between the $M_{7}$ fragment and the COX6 gene sequence (Supplementary Figure 4, section C). SNP was in coding region (Table 1; Supplementary Figure 4, section B). The SNP did not change the amino acid sequence and produced synonymous amino acid (Annotation Table). The COX6 gene is located on Watson strand of chromosome VIII and encodes for subunit IV of cytochrome C oxidase (EC 1.9.3.1; Supplementary Figure 4 Section A). The protein contained 148 amino acids and is the terminal member of the mitochondrial inner membrane electron transport chain and its expression is regulated by oxygen concentrations (SGD, 2008). Mitochondrion, the organelle that is found in all eukaryotic cells is required for cellular res- 
piration. The additional mitochondria rolls include participation in the biosynthesis of organic acids, amino acids, and phospholipids, the degradation of fatty acids and the storage of metal ions (Scheffler, 1999). Majority of the yeast genes encoding mitochondrial proteins are subject to glucose repression (DeRisi et al., 1997), and repression under hypoxic conditions (Ter Linde and Yde, 2002) which fermentation of alcoholic beverages is a good example because the concentration of glucose is high while the concentration of oxygen is low. Several studies suggested the presence of mitochondria during the fermentation of alcoholic beverages. For example, data from a genome-wide studies indicated that genes encoding mitochondrial proteins were at higher rate of expression during the brewing of sake (Japanese rice wine), one of the alcoholic beverages (Wu et al., 2006; Kitagaki and Shirnoi, 2007). Teixeira et al. (2009) indicated a high proportion of the mitochondrion- related genes were also required for ethanol stress resistance. They were mostly involved in mitochondrial protein synthesis, respiration, and mitochondrial DNA maintenance. Scheffler, (1999) and Kitagaki and Shirnoi, (2007) pointed out that it is biologically reasonable for the presence of mitochondria during alcohol fermentation. The reason is that yeast cells require to rapidly transfer from anaerobic to aerobic metabolism even in anaerobic conditions. For example when glucose is depleted and oxygen becomes available yeast cells use mitochondria to utilize the produced alcohol.

Various studies commonly agree that the first obstacle that yeast cells under ethanol stress initially struggle with is maintaining energy production which leads to an increment in expression of genes associated with energy-generating activities such as glycolysis and mitochondrial function and decrease in expression rates of many genes associated with energy demanding processes, such as growth (Stanley et al., 2010).

The desired phenotype, tolerance to high concentration of ethanol, might be related to mutations that have been observed in COX6 gene. The polymorphism observed in the COX6 gene may have resulted in molecular modifications (via EMS mutagenesis and pre-treatment to stress condition) that improved the energy-generating activities, protein synthesis, respiration, and mitochondrial DNA maintenance in mutants (Stanley et al., 2010).

\section{Conclusions}

From the molecular point of view, the polymorphisms that resulted from EMS mutagenesis might have stimulated the activation of specific molecular stress response mechanisms in mentioned genes which resulted in higher levels of resistance to stress conditions, high concentration of ethanol.

Interestingly mutant showed better growth than the wild type under the lower available carbon stress conditions caused by media derived from cellulosic biomass (Hemmati, Lightfoot and Anderson, unpublished). In future genome sequencing followed by gene knockouts and/or complementing the mutation(s) might identify the significant polymorphisms underlying the altered growth during ethanol stress.

From the fermentation point of view and future investigation of kinetics of ethanol production, it would be very valuable to evaluate the mutants' activity under the enhanced enzymatic fermentation provided by Thomas (2009). It might provide more insight to stress tolerance among mutants.

\section{Acknowledgements}

The authors would like to express the sincere appreciation to Dr. David Clark for his contribution, valuable suggestions and constructive advices throughout the research project. Dr. Navinder Saini is thanked for introducing silver staining to Dr. Lightfoot's team at SIUC (Southern Illinois University Carbondale) genomic research laboratory. Grant funding was from CFAR.

\section{References}

Aguilera A and T Benitez (1985) Role of mitochondria in ethanol tolerance of Saccharomyces cerevisiae. Arch Microbiol 142: 389.

Aguilera F, RA Peinado, C Millan, JM Ortega, and JC Mauricio (2006) Relationship between ethanol tolerance, H-ATPase activity and the lipid composition of the plasma membrane in different wine yeast strains. Int J Food Microbiol 110: 34-42.

Benitez T and AC Codon (2003) Ethanol Tolerance and Production by Yeast. Hand book of fungal Biotechnology. 20: 249-265.

Bothast RJ, NN Nichols, and BS Dien (1999) Fermentations with new recombinant organisms. Biotechnology Progress 15 (5): 867-875.

Burke D, C Dean Dawson, and T Stearns (2000) Methods in Yeast Genetics: A Cold Spring Harbor Laboratory Course Manual.

Chandler M, GA Stanley, P Rogers, and P Chambers (2004) A genomic approach to defining the ethanol stress response in the yeast Saccharomyces cerevisiae. Ann Microbiol 54: 427-454.

Chung N (1996) DNA Preparation from 10-mL Yeast Culture. http:// www.duke.edu/web/ceramide/protocols.

Coote PJ, MB Cole, and MV Jones (1991) Induction of increased thermotolerance in Saccharomyces cerevisiae may be triggered by a mechanism involving intracellular pH. J Gen Microbiol 137: 17011708.

Davies JM, CV Lowry, and KJA Davies (1995) Transient adaptation to oxidative stress in yeast. Arch Biochem Biophys 317: 1-6.

The UK Renewable Energy Strategy (2009) UK Department for Energy and Climate Change. (C) Crown Copyright.

Demain AL (2009) Biosolutions to the energy problem. J Ind Microbiol Biotechnol 36: 319-332.

DeRisi JL, VR lyer, and PO Brown (1997) Exploring the metabolic and genetic control of gene expression on a genomic scale. Science 278 : 680-686.

Dharmadhikari M (2007) Nitrogen Metabolism During Fermentation http://www.extension.iastate.edu/NR/rdonlyres/173729E4C734-486A-AD 16-778678B3E 1 CF/73941/NitrogenMetabolismDuringFermentation.pdf Vineyard and Vintage View.

Fargione J, J Hill, D Tilman, S Polasky, and P Hawthorne (2008) Land Clearing and the Biofuel Carbon Debt. Science 319: 1235-1238

Fujita K, A Matsuyama, Y Kobayashi, and H Iwahashi (2006) The genome-wide screening of yeast deletion mutants to identify the genes required for tolerance to ethanol and other alcohols. FEMS Yeast Res 6: 744-750.

Jeffries TW, and YS Jin (2004) Metabolic engineering for improved fermentation of pentoses by yeasts. Applied Microbiology and Biotechnology. 63 (5): 495-509.

Jimenez J and T Benitez (1988) Yeast cell viability under conditions of high temperature and ethanol concentrations depends on the mitochondrial genome. Curr Genet 13: 461-469. 
Jones RP (1989) Biological principles for the effects of ethanol. Enume Microb Technol 11: 130-153.

Hambourger M, GF Moore, DM Kramer, D Gust, AN Moore, and TA Moore (2009) Biology and technology for photochemical fuel production. Chem Soc Rev 38: 25-35.

Kitagaki H, and H Shirnoi (2007) Mitochondrial Dynamics of Yeast during Sake Brewing. BioSience and Bioengineering. 104: 227-230.

Meaden PG, N Arneborg, LU Guldfeldt, H Siegumfeldt, and M Jakobsen (1999) Endocytosis and vacuolar morphology in Saccharomyces cer cerevisiae are altered in response to ethanol stress or heat shock. Yeast 15: 1211-1222.

Mishra P and R Prasad (1989) Relationship between ethanol tolerance and fatty acyl composition of Saccharomyces cerevisiae. Appl Microbiol Biotechnol 30: 294-298.

Monteiro GA and I Sa' -Correia (1998) In vivo activation of yeast plasma membrane H-ATPase by ethanol: effect on the kinetic parameters and involvement of the carboxyl-terminus regulatory domain. Biochim. Biophys. Acta 1370: 310-316.

National Corn-to-Ethanol Research Center, Edwardsville, IL. (2007). http://www.ethanolresearch.com.

Ogawa Y, A Nitta, H Uchiyama, T Imamura, H Shimoi, and K Ito (2000) Tolerance mechanism of the ethanol-tolerant mutant of sake yeast. J Biosci Bioeng 90: 313-320.

Plesset J, C Palm, and CS McLaughlin (1982) Induction of heat shock proteins and thermotolerance by ethanol in Saccharomyces cerevisiae. Biochem Biophys Res Commun 108: 1340-1345.

Rak M, E Tetaud, F Godard, I Sagot, B Salin, S Duvezin-Caubet, PP Slonimski, J Rytka, and JP di Ragol (2007) Yeast Cell Lacking the Mitochondrial Gene Encoding the ATP Synthase Subunit 6 Exhibit the Selective Loss of Complex IV and Unusual Mitochondrial Morphology. The American Society for Biochemistry and Molecular Biology, Inc. JBC Papers in Press. Manuscript M608692200.

Rosa MF and I Sa'-Correia (1991) In vivo activation by ethanol of plasma membrane ATPase of Saccharomyces cerevisiae. Appl. Environ. Microbiol. 57:830-835.

Saccharomyces Genome Database, (2010) http://db.yeastgenome. org.

Salgueiro SP, I Sa'-Correia, and JM Novais (1988) Ethanol-induced leakage in Saccharomyces cerevisiae: kinetics and relationship to yeast ethanol tolerance and alcohol fermentation productivity. Appl Environ Microbiol 54: 903-909.

Sanchez Y, and SL Lindquist (1990) HSP 104 required for induced thermotolerance. Science 248: $1112-1115$.

Scheffler IE (1999) Mitochondria. Wiley-Liss, New York. pp. 1-5.

Stanley D, A Bandara 1, S Fraser, J Chambers, and GA Stanley (2010) The ethanol stress response and ethanol tolerance of Saccharomyces cerevisia. Journal of Applied Microbiology. 109: 13-24.

Stephenson PG, M Moore, MJ Terry, MV Zubkov, and TS Bibby (2011) Improving photosynthesis for algal biofuels: toward a green revolution. Trends in Biotechnology. Cell Press 29: 615-623.

Ter Linde JJM, and SH Yde (2002) A microarray-assisted screen for potential Hapl and Roxl target genes in Saceharomyces cetevisiae. yeast. 19: 825-840.

Teixeira MC, LR Raposo, NP Mira, AB Lourenço, and I Sá-Correia (2009) Genome-Wide Identification of Saccharomyces cerevisiae genes required for maximal tolerance to ethanol. Applied and Environmental Microbiology 75: 5761-5772.

Trollmo C, L Andre, A Blomberg, and L Adler (1988) Physiological overlap between osmotolerance and thermotolerance in Saccharomyces cerevisiae. FEMS Microbiol Lett 56: 321-326.

Thomas AB, Al-Dahhan M, M Dudukovic, J Gleaves, D Johnston, Ph Ramachandran, J Turner, C Woods (2009) Enzymatic Enhancement of Water Removal In the Dry Grind Corn to Ethanol Process. Washington University in St. Louis. Electronic Theses and Dissertations.

Van Uden N (1986) Ethanol toxicity and ethanol tolerance in yeast. Ann Rep Fermen Proc 8: 11-58.

Van Uden N (1989) Alcohol Toxicity in Yeasts and Bacteria. Boca Raton, FL., CRC Press, Inc.

Varela JC, C van Beekvelt, RJ Planta, and WH Mager (1992) Osmostress-induced changes in yeast gene expression. Mol Microbiol 6: 2183-2190.

Vriesekoop F and NB Pamment (2005) Acetaldehyde addition and preadaptation to the stressor together virtually eliminate the ethanolinduced lag phase in Saccharomyces cerevisiae. Lett Appl Microbiol 41: 424-427.

Wu B, X Zheng, Y Araki, B Sahara, B Takagi, and B Shimoi (2006) Global gene expression analysis of yeast cells during sake brewing. Appl. Environ Microb 72: 7353-7358. 


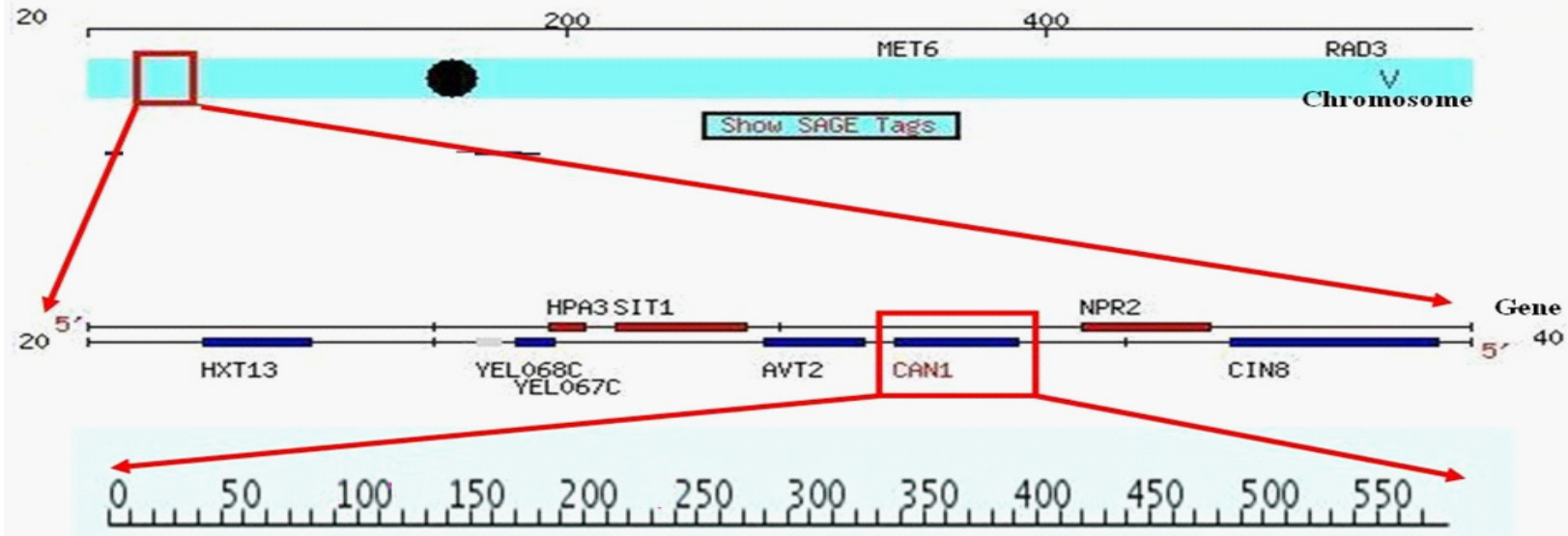

Protein

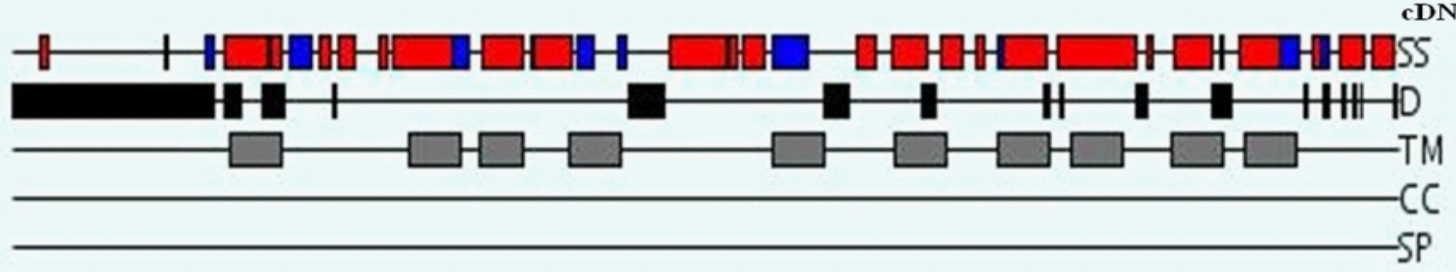

DNA

Supplementary Figure 1. Section A: Ideogram of the CAN1 gene on chromosome $V$ and a snapshot of predicted structural information about the protein/cDNA sequence. A legend on the right-hand side of the image indicates what data that section of the image is displaying. SS: Secondary Structure, D: Disordered Regions, TM: Transmembrane Regions, CC: Coiled Coil Regions and SP: Signal Peptide. Cited from Saccharomyces Genome Database, SGD, and Yeast Resource Center, YRC.

\section{Section B:}

ggatccgatccagttttaatctgtcgtcaatcgaaagtttatttcagagttcttcagacttcttaactcctgtaaaaacaaaaaaaaaaaggcat agca $\mathbf{A} \mathbf{T}$ aca aat tca aaa gaa gac gec gac ata gag gag aag cat atg tac aat gag ecg gtc aca acc ctc ttt cac gac gtt gaa get tca caa aca cac cac aga cgt ggg tca ata cca ttg aaa gat gag aaa agt aaa gaa ttg tat cca ttg cge tet ttc ccg acg aga gta aat gge gag gat acg ttc tct atg gag gat gge ata ggt gat gaa gat gaa gga gaa gta cag aac get gaa gtg aag aga gag ctt aag caa aga cat att ggt atg att gec ctt ggt ggt act att ggt aca ggt ctt ttc att ggt tta tcc aca cet ctg acc aac geC gge cca gtg gge get ctt ata tca tat tta ttt atg ggt tet ttg gea tat tet gtc acg cag tce ttg ggt gaa atg get aca ttc atc cet gtt aca tcc tet ttc aca gtg ttc tca caa aga ttc ctt tet cca gea ttt ggt geg gec aat ggt tac atg tat tgg ttt $\mathbf{t}$ ct tgg gea atc act ttt gec ctg gaa ctt agt gta gtt gge caa gtc att caa ttt tgg acg tac aaa gtt cca ctg geg gea tgg att agt att ttt tgg gta att atc aca ata atg aac ttg ttc cet gtc aaa tat tac ggt gaa ttc gagttctgggtcgettccatcaaagttttagccattatcgggtttctaatatactgttttgtatggtttgtggtgetggggttaccggeccagttgg attccgttattggagaaacccaggtgectggggtccaggtataatatctaaggataaaaacgaagggaggttcttaggttgggttcctctttg attaacgetgecttcacatttcaaggtactgaactagttggtatcactgetggtgaagetgcaaaccccagaaaatccgttccaagagecatca aaaaagttgttttccgtatettaaccttctacattggetctetattattcattggacttttagttccatacaatgaccetaaactaacacaatctacttc ctacgtttctacttctecetttattattgetattgagaactetggtacaaaggttttgecacatatettcaacgetgttatcttaacaaccattatttctg ccgcaaattcaaatatttacgttggttcccgtatttatttggtctatcaaagaacaagttggetcctaaattcctgtcaaggaccaccaaaggtg gtgttccatacattgcagttttcgttactgetgcatttggcgetttggettacatggagacatctactggtggtgacaaagttttcgaatggetatta aatatcactggtgttgcaggetttttgeatggttatttatctcaatctcgcacatcagatttatgcaagetttgaaataccgtggeatctctcgtga cgagttaccatttaaagetaaattaatgeccggettggettattatgeggecacatttatgacgatcattatcattattcaaggtttcacggettttg caccaaaattcaatggtgttagetttgetgecgectatatetetgttttcetgttettagetgtttggatettatttcaatgcatattcagatgeagattt atttggaagattggagatgtcgacatcgattccgatagaagagacattgaggcaattgtatgggaagatcatgaaccaaagacttttgggac aaattttggaatgttgtagca $\mathbf{T} \mathbf{A}$ atatgacgttttattacetttaatcacattcccacgecatttcgcattctcaccetcataagtcatacac cgaaaagaaagtttaagggatcaatgagettactataatctcagtatatttattttatcgatgattcaccacaacaatcttgetccegaaaagaa agcagacggagtacaa

Supplementary Figure 1. Section B: CAN1 gene coding region is marked by start codon ATG and stop codon TAG in larger and bold fonts. The region that $C 2$ segment matches with CAN1 gene is highlighted in gray. Section C: The gray region from section $A$ is aligned with C2 segment and polymorphisms are marked by larger and bold fonts. 


\section{Section C:}

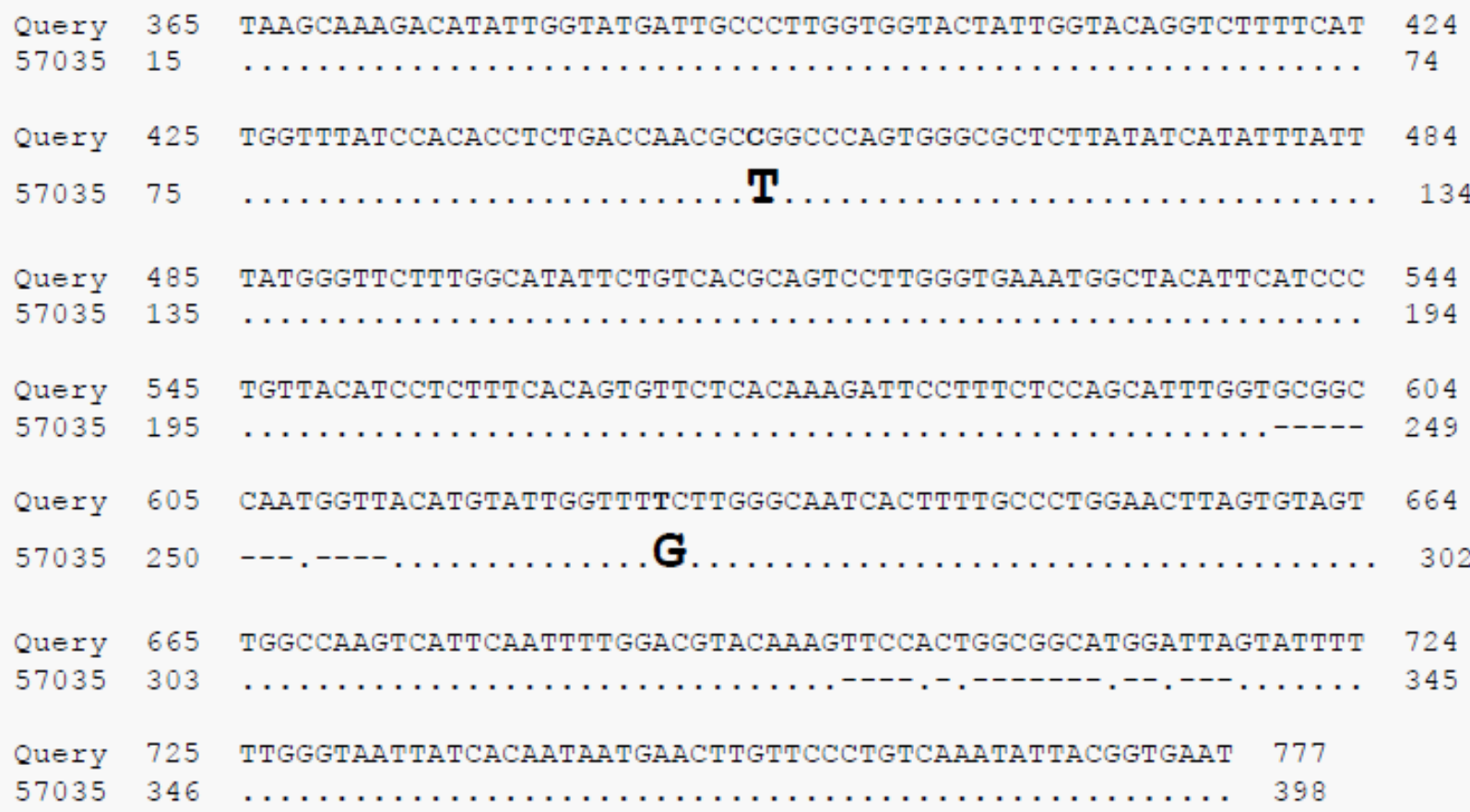

Supplementary Figure 1, Section C: The gray region from section A is aligned with C2 segment and polymorphisms are marked by larger and bold fonts.

\section{Section D:}

Ggatccgatccagttttaatctgtcgtcaatcgaaagtttattcagagttcttcagacttcttaactcetgtaaaaacaaaaaaaaaaaaggca tagca atg aca aat tca aa gaa gac gec gac ata gag gag aag cat atg tac aat gag ccg gtc aca acc ctc ttt cac gac gtt gaa get tca caa aca cac cac aga cgt ggg tca ata cca ttg aaa gat gag aaa agt aaa gaa ttg tat cca ttg cge tct ttc ccg acg aga gta aat gge gag gat acg ttc tct atg gag gat gge ata ggt gat gaa gat gaa gga gaa gta cag aac get gaa gtg aag aga gag ctt aag caa aga cat att ggt atg att gec ctt ggt ggt act att ggt aca ggt ctt ttc att ggt tta tcc aca cet ctg acc aac gec gge cca gtg gge get ctt ata tca tat $\mathrm{tta}$ tt atg ggt tet ttg gea tat tet gtc acg cag tcc ttg ggt gaa atg get aca ttc atc cet gtt aca tcc tct ttc aca gt $\mathbf{g}$ ttct cac aaa gat tce ttt ctc cag cat ttg gtg cgg cea atg gtt aca tgt att ggt ttt ctt ggg caa t cactttgecetggaacttagtgtagttggccaagtcattcaattttggacgtacaaagttccactggeggcatggattagtattttttgggtaatta tcacaataatgaacttgttccctgtcaaatattacggtgaattcgagttctgggtcgettccatcaaagtttagccattatcgggtttctaatatact gttttgtatggtttgtggtgetggggttaccggcccagttggattccgttattggagaaacccaggtgectggggtccaggtataatatctaag gataaaacgaagggaggttcttaggttgggtttcctctttgattaacgetgccttcacatttcaaggtactgaactagttggtatcactgetggt gaagetgcaaaccccagaaaatccgttccaagagccatcaaaaa gttgttttcegtatcttaacettctacattggetctctattattcattgga cttttagttccatacaatgaccctaaactaacacaatctacttcctacgtttctacttctccetttattattgetattgagaactctggtacaaaggtttt gccacatatcttcaacgetgttatcttaacaaccattatttctgecgcaaattcaaatatttacgttggttccegtatttatttggtctatcaaagaac aagttggctcctaaattcctgtcaaggaccaccaaaggtggtgttccatacattgcagtttcgttactgetgcatttggcgetttggettacatg gagacatctactggtggtgacaaagttttcgaatggetattaaatatcactggtgttgcaggetttttgcatggttatttatctcaatctcgcacat cagatttatgcaagetttgaaataccgtggcatctctcgtgacgagttaccatttaaagctaaattaatgeceggettggettattatgeggccac atttatgacgatcattatcattattcaaggtttcacggetttgcaccaaaattcaatggtgttagetttgetgecgectatatctctgttttcetgttct tagctgtttggatcttatttcaatgcatattcagatgcagatttatttggaagattggagatgtcgacatcgattccgatagaagagacattgagg caattgtatgggaagatcatgaaccaaagacttttgggacaaatttggaatgttgtagca tagatatgacgttttattacctttaatcacattc ccacgecatttcgcattctcaccctcataagtcatacaccgaaaagaaagtttaagggatcaatgagettactataatctcagtatatttatttttat cgatgattcaccacaacaatcttgctccegaaaagaaagcagacggagtacaa

Supplementary Figure 1. Section D: CAN1 gene coding region is marked by start codon ATG and stop codon TAG in larger and bold fonts. The region that $M 4$ segment matches with CAN1 is highlighted in gray. Section E: The gray region from section $A$ is aligned with $M_{4}$ segment and polymorphisms are marked by larger and bold fonts. 


\section{Section E:}

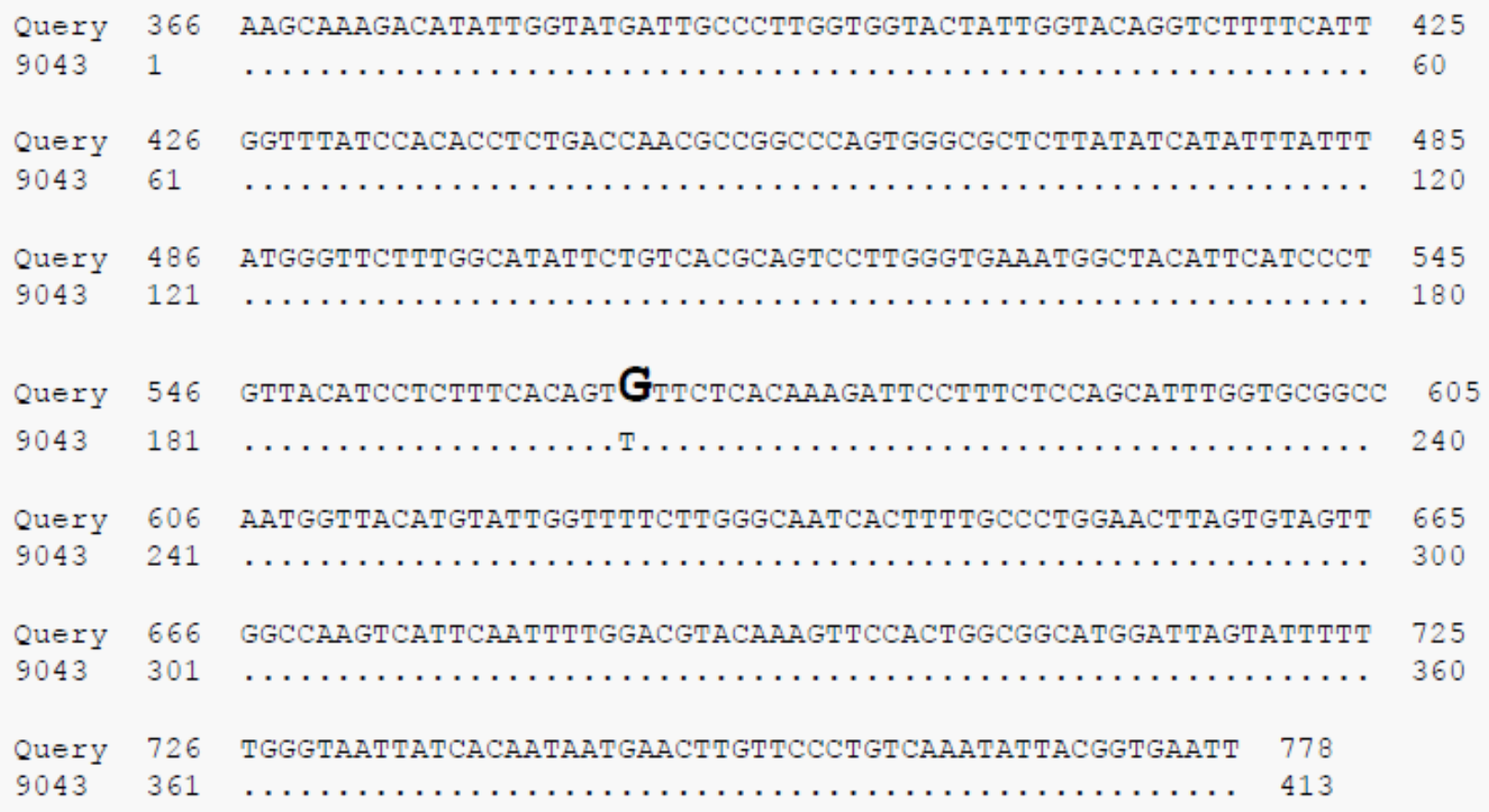

Supplementary Figure 1. Section E: The gray region from section $A$ is aligned with $M_{4}$ segment and polymorphisms are marked by larger and bold fonts.

\section{Section F:}

Ggatccgatccagttttaatctgtcgtcaatcgaaagtttattcagagttcttcagacttcttaactcctgtaaaaacaaaaaaaaaaaggca tagca atg aca aat tca aaa gaa gac gec gac ata gag gag aag cat atg tac aat gag ceg gtc aca acc ctc ttt cac gac gtt gaa get tca caa aca cac cac aga cgt ggg tca ata cca ttg aaa gat gag aaa agt aaa gaa ttg tat cca ttg cge tet ttc ccg acg aga gta aat gge gag gat acg ttc tct atg gag gat gge ata ggt gat gaa gat gaa gga gaa gta cag aac get gaa gtg aag aga gag ctt aag caa aga cat att ggt atg att gec ctt ggt ggt act att ggt aca ggt ctt ttc att ggt tta tcc aca cet ctg acc aac gec gge cca gtg gge get ctt ata tca tat tta ttt atg ggt tet ttg gea tat tet gtc acg cag tce ttg ggt gaa atg get aca ttc atc cet gtt aca tcc tct ttc aca gtg ttc tca caa aga ttc ctt tet cca gca ttt ggt geg gec aat ggt tac atg tat tgg ttt tet tgg gca atc act $\mathrm{ttt}$ gccetggaacttagtgtagttggccaagtcattcaattttggacgtacaaagttccactggeggcatggattagtatttttgggtaattatcaca ataatgaacttgttccetgtcaaatattacggtgaattcgagttctgggtcgettccatcaaagttttagecattatcgggtttctaatatactgttttt gtatggtttgtggtgetggggttaccggcccagttggattcegttattggagaaacccaggtgectggggtccaggtataatatctaaggataa aaacgaagggaggttcttaggttgggttcctctttgattaacgetgecttcacattcaaggtactgaactagttggtatcactgetggtgaagc tgcaaaccccagaaaatccgttccaagagccatcaaaaaagttgttttcegtatcttaacettctacattggetctctattattcattggacttttag ttccatacaatgaccetaaactaacacaatctacttcctacgtttctacttctccetttattattgetattgagaactctggtacaaaggttttgccac atatcttcaacgetgttatcttaacaaccattatttctgecgcaaattcaaatatttacgttggttccegtattttattggtctatcaaagaacaagtt ggetcctaaattcctgtcaaggaccaccaaaggtggtgttccatacattgcagttttegttactgetgcatttggegetttggettacatggagac atctactggtggtgacaaagtttcgaatggetattaa atcactggtgttgcaggetttttgcatggttatttatctcaatctcgcacatcagatt tatgcaagettgaaataccgtggcatctctcgtgacgagttaccatttaaagctaaattaatgeceggettggettattatgeggecacatttat gacgatcattatcattattcaaggttcacggetttgcaccaaaattcaatggtgttagetttgetgecgectatatctetgttttectgttcttaget gtttggatcttattcaatgcatattcagatgcagatttatttggaagattggagatgtcgacatcgattccgatagaagagacattgaggcaatt gtatgggaagatcatgaaccaaagacttttgggacaaatttggaatgttgtag $\mathbf{l}$ catagatatgacgttttattacetttaatcacattcccac gecatttcgcattctcaccetcataagtcatacaccgaaaagaaagtttaagggatcaatgagettactataatctcagtatatttattttatcgat gattcaccacaacaatcttgetcecgaaaagaaagcagacggagtacaa

Supplementary Figure 1. Section F: CAN1 gene coding region is marked by start codon ATG and stop codon TAG in larger and bold font. The region that $M_{5}$ segment matches with CAN1 is highlighted in gray. 


\section{Section G:}

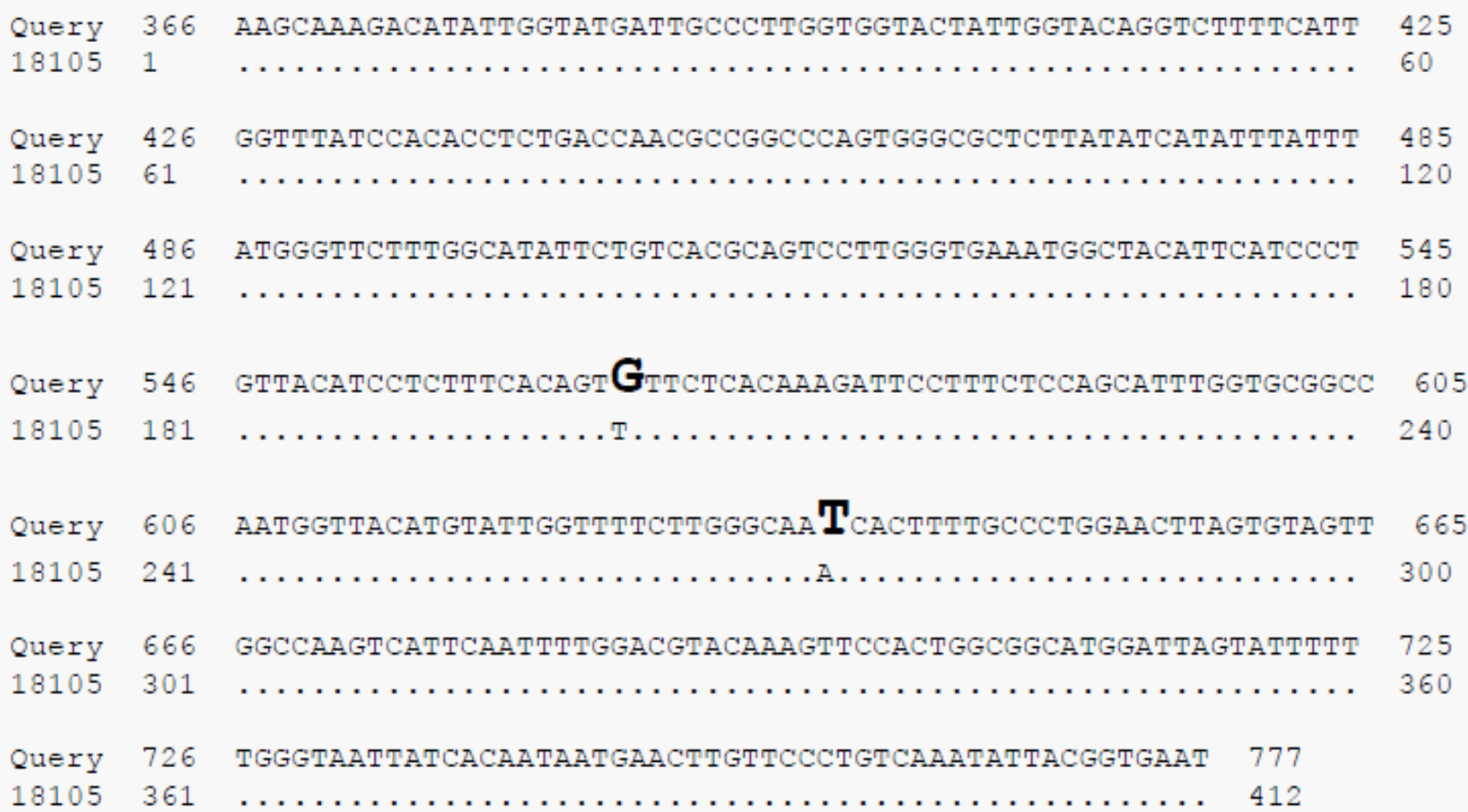

Supplementary Figure 1. Section G: The gray region from section A is aligned with $M_{5}$ segment and polymorphisms are marked by larger and bold font.

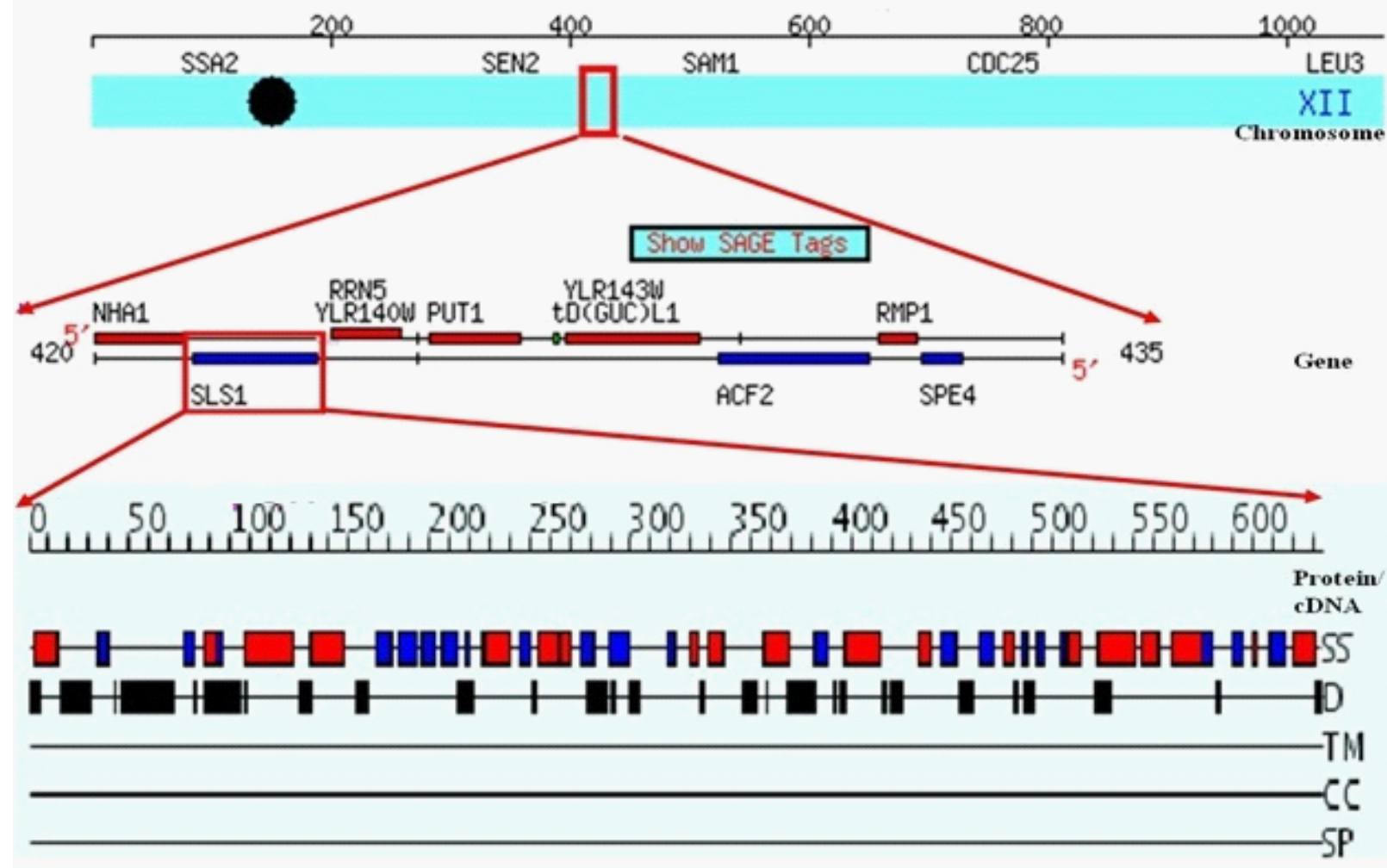

Supplementary Figure 2, Section A: Ideogram of the SLS1 gene on chromosome XII and a snapshot of predicted structural information about the protein/cDNA sequence. A legend on the right-hand side of the image indicates what data that section of the image is displaying. SS: Secondary Structure, D: Disordered Regions, TM: Transmembrane Regions, CC: Coiled Coil Regions and SP: Signal Peptide. Cited from Saccharomyces Genome Database, SGD, and Yeast Resource Center, YRC. 
Section B:

Taccegcettttcatggatgetctttacatgtactttggaaggatggaactcagetgggeggectgacgeggcaccattgtagaattcetcga cetccttattgtacaattcgacgtacttecgcaattgttggtgetccatcctaggtgacegtcgtatgegetgtgetttectagetcttcttccacttc tgtttctctatactttttttttgttttcacetcgecegecttttcttatttcagtgaactgaaaaaaaaaaaaaa gttatgtatctttaatgtaa taaaa

ctagtacataatatatacggagettgaaggcactggagaaaatatagagtaagcat atg tgg aaa ttc aac aaa aag ctc gec cgt ctt act tac cgt ctt tat tca agc tca gge cca agc teg cce ct cat ggg aag aag aaa ctg ccg caa aat ctg aaa ttc gtc gtc ttg aac cet acc caa tct ggg cta gtg aaa aat gat cag aag cag cet aga cac agg ccg tct aag aaa cgt agc cat aag gaa act gga gat aac aac ctc gat ttc gge tcg aaa ctc ctt gtc ttc gaa aag cag aat tca cta gat tcc gea ttg aac tcc atc cga ttg aa $\mathbf{g}$ aaa $c c g$ aca agc gec agt ctg cce tec ct $\mathbf{g}$ gaa tac aatgecettctccaatcgettacatcaagetacaatcgetaccaactgegegagttcatctccacacatcagccagactcetcttcacatctgac gcactggaagaaaa gcaagetgtcccaatatataattgaaaaa tetggaattgccaaccaatttcaacacccaccactcceacaggcatca agtccacatcattgactttccagttcgattctcctagagaaatttcettttactcatcactcaaaatggtaaaatactcaccaacttcaataagetc gggetgacattcatcatctccattcaggataacgaattgaccgtcaagggttcgectagettgetcaaatacgcagaaatatccttaaacaaaa

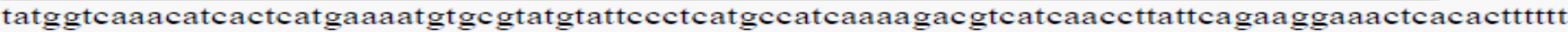
tgaatacctcceggacttgcaaatgtacaagatttcagecetaagcaccaagaaaatatccatggecaaagtctttttattaaatgecgtcgett ctaatcctaacacaactcaacaccaccacacaatagcctcaccagcactcaagacagaactctatecgttcaacaatactctagagaacttgg actggctaaacaagtcacaagattgggcaagattacagtcagttgtccetaaaaattgcacagatctgatgactcccactgaaaacgecaca

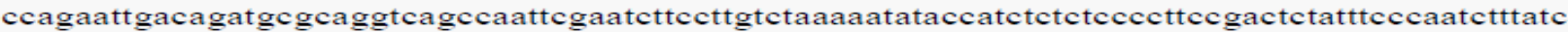
aataacgetaggtcactccttacagtcegegtcttttctagtattttccaacctctaatacataagagttttattcaaaattactgaatctaccaat gtacaaagaatcatcatcatcagecgtacetgtgectgtgectcttgatcaacatctaataacaaatgegcatcaatccttcatacagetgaact tcactcctgtgecgeccacctctggetcctcctegtccectttttgeagatttggttcgagattgacgaattcgataacattgttaccacctcaat gaggcetctttgaaattacaagaaaattctgttatcttaagaactccacaatgccagacagactataagatcacgtcagattacattcaagatct tttacctgatttcgaccagaccaatccggatgettggttatctgaacaaaaaggcctccaagaatttcttctcaagtcacactggaagttaaaca aatatcagaatcttatgaaaaaa tcaacatttctttaccagataacctaatacagcaataccaattgactgatgtttgacceatcgtgtcttgaat ttacgatttcctacgaacactgeccaagatgataa tacatcattcaatattcagatatcagecgeggattttgaacaatggetcetacagaca

attagatttcatcaatgtgaaccccagtgaaacctcactaaaa cetttatcaatgatgttttaagettt $\mathbf{t a} \mathbf{a}$ gtttaacggaaaagagtaatga caaaacegcatacceccececetccectetttaccgeatctactctatttcegacacatgtaaataaaaaaggeatttcgtttatatatatacta aa ataatatatctttgtgtattaataa attacttattgagaccaagcgttttgatagegecgacttaacagcagcactcttttgacttttttttt

Supplementary Figure 2, Section B: SLS1 gene coding region is marked by start codon ATG and stop codon TAA in larger and bold fonts. The region that $M_{2}$ segment matches with SLS1 is highlighted in gray.

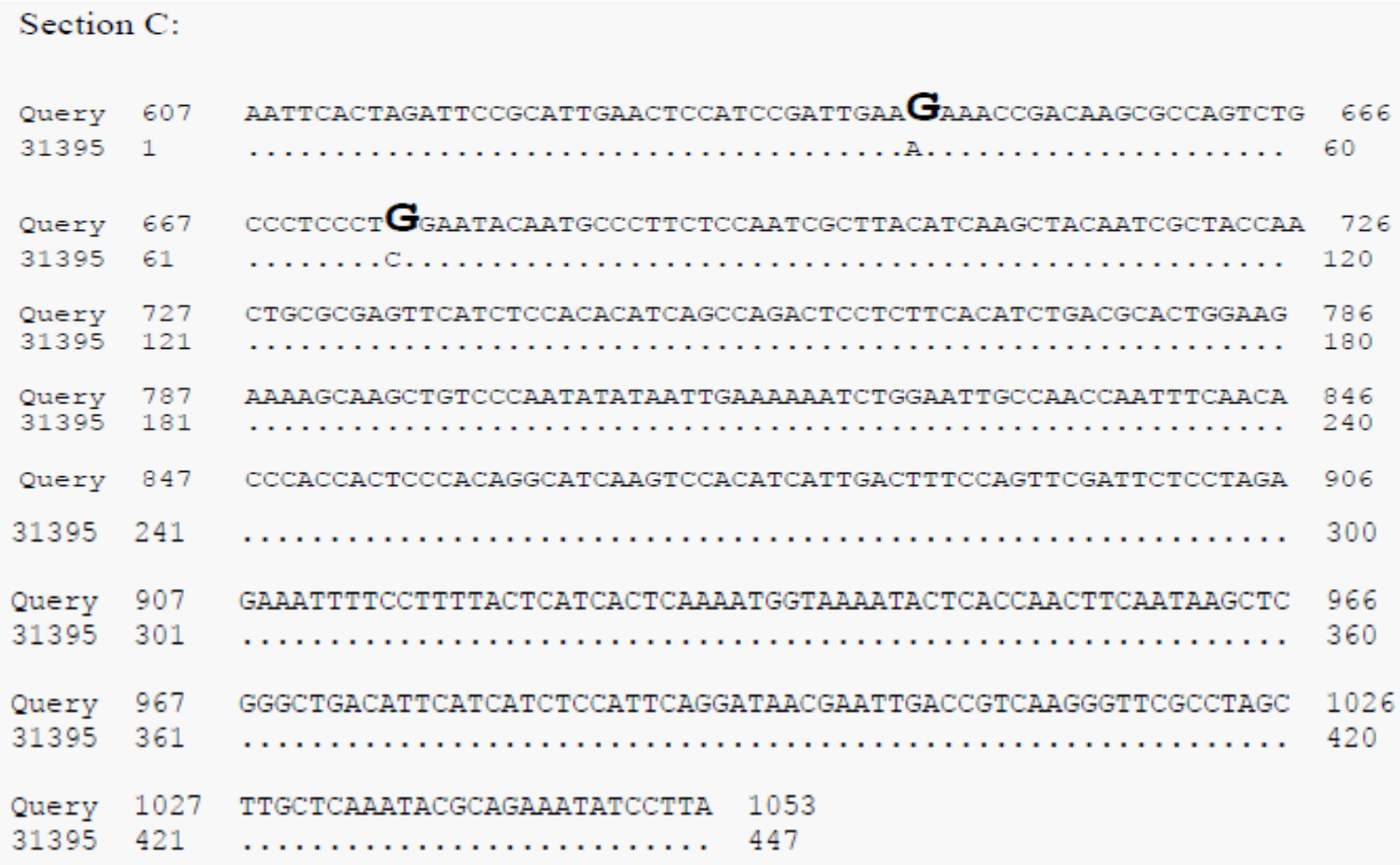

Supplementary Figure 2. Section C: The gray region from section A is aligned with $M_{2}$ segment and polymorphisms are marked by larger and bold fonts. 


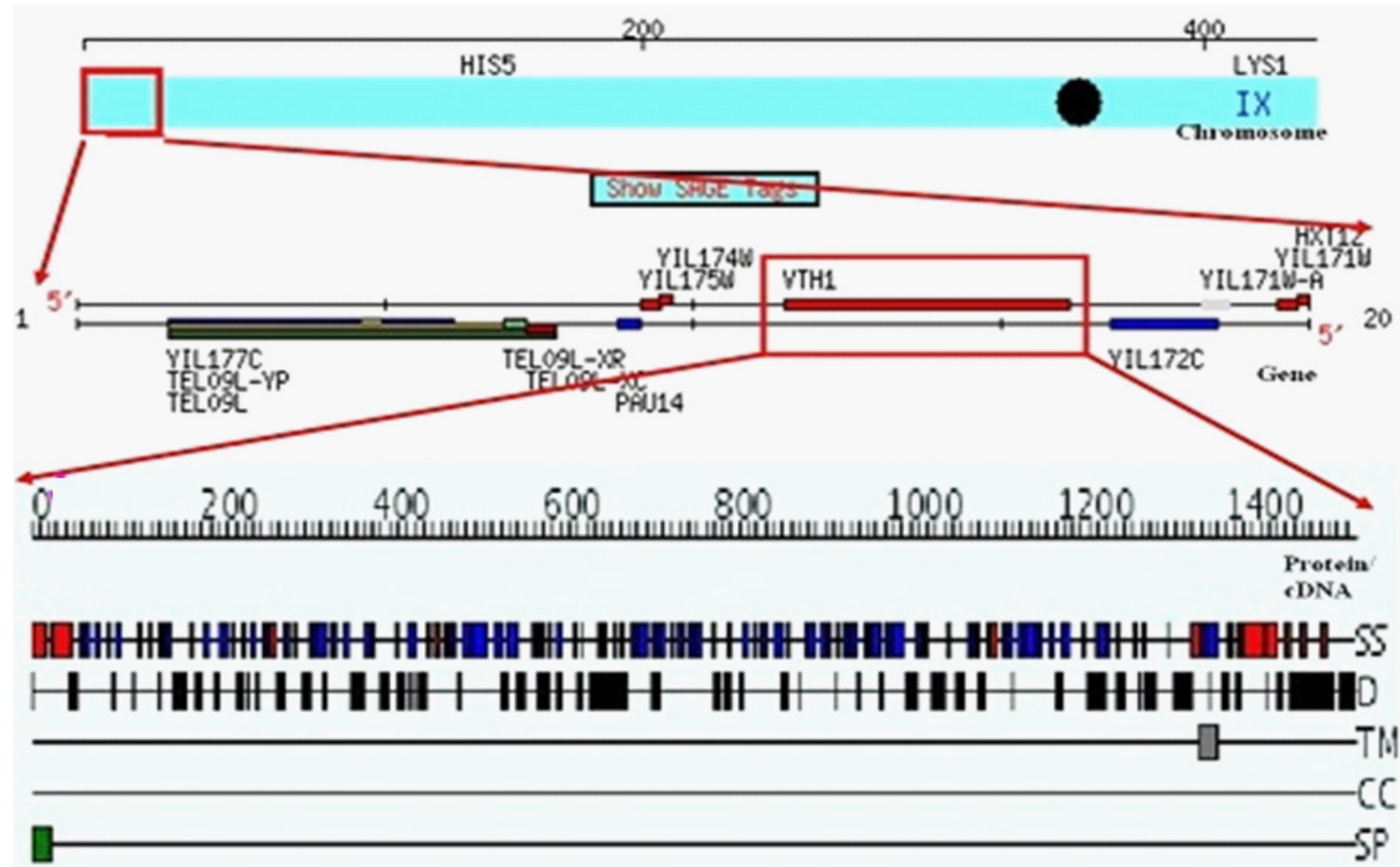

Supplementary Figure 3, Section A: Ideogram of the VTHI gene on chromosome IX and a snapshot of predicted structural information about the protein/CDNA sequence. A legend on the right-hand side of the image indicates what data that section of the image is displaying. SS: Secondary Structure, D: Disordered Regions, TM: Transmembrane Regions, CC: Coiled Coil Regions and SP: Signal Peptide. Cited from Saccharomyces Genome Database, SGD, and Yeast Resource Center, YRC. 
Atggeattgtttcgtgecetgtatattattgggtattcetactcattccactgtcca atg cag aag aat tca ccc cca ag gtt acc aga act ttg tca aga tat gta ttc gat ata gta aac ttt gat gat tca aac act ttg atc aga gea gaa gaa gac tct gtc gag ata agt ttt gat get gga gaa aat tgg aaa aca ata gat gag att gaa gag cet atc gag tca ttt gtt gtt gat cec ttc cgt ggg cat gat aga get ttt get ttc gtg aaa acg gca cca aaa tt tac gtc acg gat gat caa ggt aaa tcg tgg agg cet ttg act ata cce att tet gag aaa gea tcg aat tat t t t tge gac gta act act cac cet ata aaa aag aag cat ctt att att cgt tgt gat ttg ttg aca ata aaa ac tca gge tta

atgtatgttggaagagagatttacacaactaatgatggagtatcettttcccaagttaaacettctttggaaaaattgatggtcatattagcacgg cacgetgtgactttattaaatctagtgaggattctgatctgggeggtaatgatgettcgatactctgtctttccgaaacactgagtacattgaaag tacaggctcaactattgacaagtctgaattgattttaagtgccgatggaggtgaaacattcaaagaattagtccagttcaaagataaggttgtta gtcgatacgagatacttaagcatcatgtgatcgtttgacacaagatgatatgtataatgaaatgtcatcaacaaacatttggatatccaatgatg tatccactttcaagtggetcgtacacctactaagatacggcacgttaatatgggacaaattcatgaagattccatcggaagaatcgtttacctg tatctagagaaagagatgatgaagacagcaaccaaccgggagctgetgaagtgttaatatcagattctgaaggactaaaattttgcetataa attggataccaaacaatcagtttggatatatcaatgtagettatccaggtttcttaaaaggaacatttttggttcgtttcatccettcattgaatattc tgatagaaaaaggaaatacagccgacagaaagtaagagaggaaactaaagtatetgttgataacggtctcacatggacaaacttgaaagtt gttgaccgggaaaatgtagatttattggttgtgatgtcactaaacccgagagatgttcgettcagactcatttctatgatctaagaaattaaatc cctctgecggaatcatgatgatatcgggtattgttggcgacggcagtgcatacaattggaaagaagaaaaactttcatctccagggatagtg gtttaacatggaggttagtccataattccactggtttatatactactggtgatctgggaaatattatcatgtatattccatatcgttcgaatgaaaat ggcgatgtgccttctaaattttattattccttggatcaaggtaagacatggggtgaatatgatctaatcatgcctatttatccatacagattagtcag cacaatatcagatggatctggttcaaaattattctaacaggaacgtccattacagaagatccaatattcattacatattcaattgattttcagcgg tattgattataa tcatgtgaagagggtgatttgaagattggaatctagcagatggaaaatgtgttaatggegccaaatacaagtacagaag gaggaaacaggacgcccagtgtttggtaaaaaagcattcaaagatttgagtttagatgaaacgecttgtaacagttgtactggatccgacta cgaatgttcgtttgaattcgttagagatgcgaagggtgactgtataccagattataatctgattgecetttccgatatatgtgacaaatcgaaggg taaatctgtgttagtaaagccactacaattaatcaaaggtgataaatgtaaaacacctatgaaaattgaatccgtagacattccgtgtgacgaaa ttccaaaggagggttcgagtgacaaggaaatagtgactactgaaaacaaattcgactttgaaattaaatttaccaatacttcgatacagttgcc gacgaatcttggtcatgetgaattcgataggagacgectatatatcccacgatggtggacaaacgataaaaaggtttgacactgacggcga aaaattgtcgaaatcgtgtttaacccatacttcaattcttcagcatatttgtttggctctaaaggtaacatattcttaacacacgatagaggatact ctttcatgatagctaaattacctgaagccaggcaattaggcatgccactagattttagtgctaaagcacaggatactttatttactatggtggtaa gaattgtgaatcaattttaagtccagaatgtcatgcagtggcatacctcaccaaagatgggggtgaaactttacagaaatgcttgataatgca attcattgtgagtttgcaggaacactattcaaatatccgtcaa tgacgatatggttatgtgccaagtaaaggaaaagttttcgcaaacaagaag tttagtttcttctactgactttttccaagatgatagaaaaactgtctttgaaaacattatcggetacttgtctactggtggetatatcattgttgecgta cctcatgaagacaatgaattgagggegtatgtaactaatgatggtgetgagtttaccgaggcaaaattcccatatgatgaagatattggtaagc aagacgcattcactatttaggatctgaggaaggatcaatattttacatttagcaacaaacttggaatcaggacacgatttcggaaaccttttga aatccaactcgaatggtacttctttgtcaccttagagcatgecgttaatagaaacacattcggttatgtggactttgaaaaagttcaaggtcttga aggtattattatcaccaacatcgtttcgaatagcgaaaaggttggegagaacaaggaagacgaacaattgaagacgaaaatcaccttcaatg acggttcagattggaacttttgaagcctccaaagaaggattcggaagggaaaaagtttccetgtgattctgtgtcattagataaatgttctctac attgcatggttacactgaacgtaaggatatcagggatacatattcctctggctccgcgttaggaatgatgtttggtgtcggaaatgttggcgat aggettctaccatatgaggagtgttccactttctaaccactgatggaggagagacgtggactgaggttaaaaaaggeccccatcaatggga gtacggtgatcatggtggagtcttggttttggtccccgaaaacgcagaaactgattctatttcttactccaccgatttggtaaaacatggaaag attataaattctgtggegacaaagtcctcgtaaaggatataatcaccgttcccagagattctgetttgaggttttgetatttggagaagcaaaaa acatgggtagtggttcattcagaacgtatacaattgattttagaaacatcttcgagaggeaatgtgagtttgatattaccggtagaaaaaggge agatttaagtactctcctctgggttccagaactggttgtttgtttggccataaaacagaattttacgtaaaaccgatgaaaaatgttttattggga atattccactttctgaattttcgaggaacgtcaaaa ctgtccatgtacaagacaagatttcgaatgtgactataattttataaagccagtgatgg tacttgtaaattagtcaaaggettaagttcggegaatggtgecgatatctgcaaaaaggaaccegacttaattgaatactatgattcetccgget

atcggaaaattccettatcaacctgtaaaggtgggetgaaattggatgcacatttagcaccacatccttgtccgggaaaagaaaggcattca gggaaaatactctataaacaccggcgettatgcgetggttttgttacaattcttctcgttatttctttgtcgcatggtttgtatacgatagaggta tcaggagaaatgggggattttcaagatttgaagaaatcagattaggagacgatgggetgatagaaaacaataggaccgatagagttgtcaa catcattgtaagactaggattatgcatttcttaatcaccaagtctgcgttcaacgcgcgaaggcaggtacagcgcaacttcttcaaaatttag ggcaaggtttggcaacaaaaaggtgccacttactcttcgctgcttcatgatcagctttcagatgaaccagatggettccatgaagattccaac gatttatccagtttcagaggtcaaggtagtaattctgaaattgagcaagaagatgttgacacatctcaacaagagcatacgttgcggacagac ctacttggtgctagcaatattccagacgcttgccagegegtagtgettctcacgagtccgatttagcagctgcacgcagcgaagacaagta

g

Supplementary Figure 3. Section B: VTH1 gene coding region is marked by start codon ATG in larger and bold fonts. The region that $M_{3}$ segment matches with $\mathrm{VTH} 1$ is highlighted in gray. 
Section C

445531

AATTCACCCCCAAGGTTACCAGAACTTTGTCAAGATATGTATTCGATATAGTAAACTTTG

127

Q

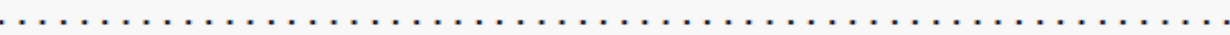

60

Query 128 ATGATCAAACACTTTGATCAGACAGA.GA.GACTCTGTCGAGATAAGTTTGATGCTG 187

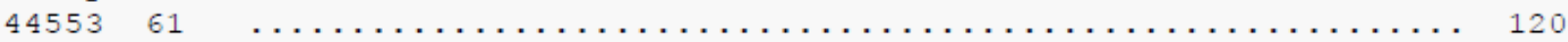

Query 188 GAGA_A.ATGGA_A_ACATAGATGAGATTGA_GAGCCTATCGAGTCATTTGTTGTTGATC 247

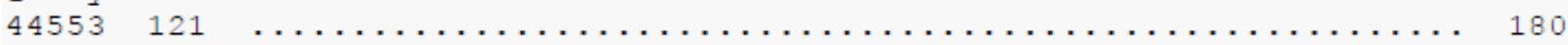

Query 248 CCTTCCGTGGGCATGATAGAGCTTTTGCTTTCGTGA.AACGGCACCAAAATTTACGTCA 307

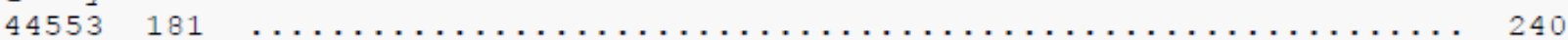

Query 308 CGGATGATCAAGGTAAATCGTGGAGGCCTTTGACTATACCCATTTCTGAGAAAG---CAT 364

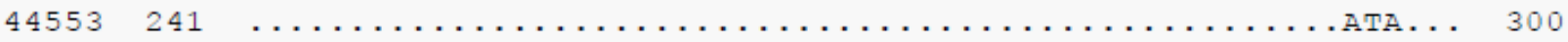

Query 365 CGA.TTATTTTGCGACGTAACTACTCACCCTATAдAдA.GA.GCATCTTATTATTCGTT 424

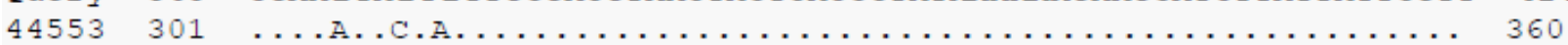

Query 425 GTGATTGTtGACAATAAAAACtCAGGCTtA 456

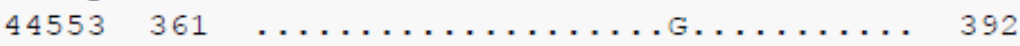

Supplementary Figure 3. Section C: The gray region from section A is aligned with $M_{3}$ segment and polymorphisms are marked by larger and bold fonts.

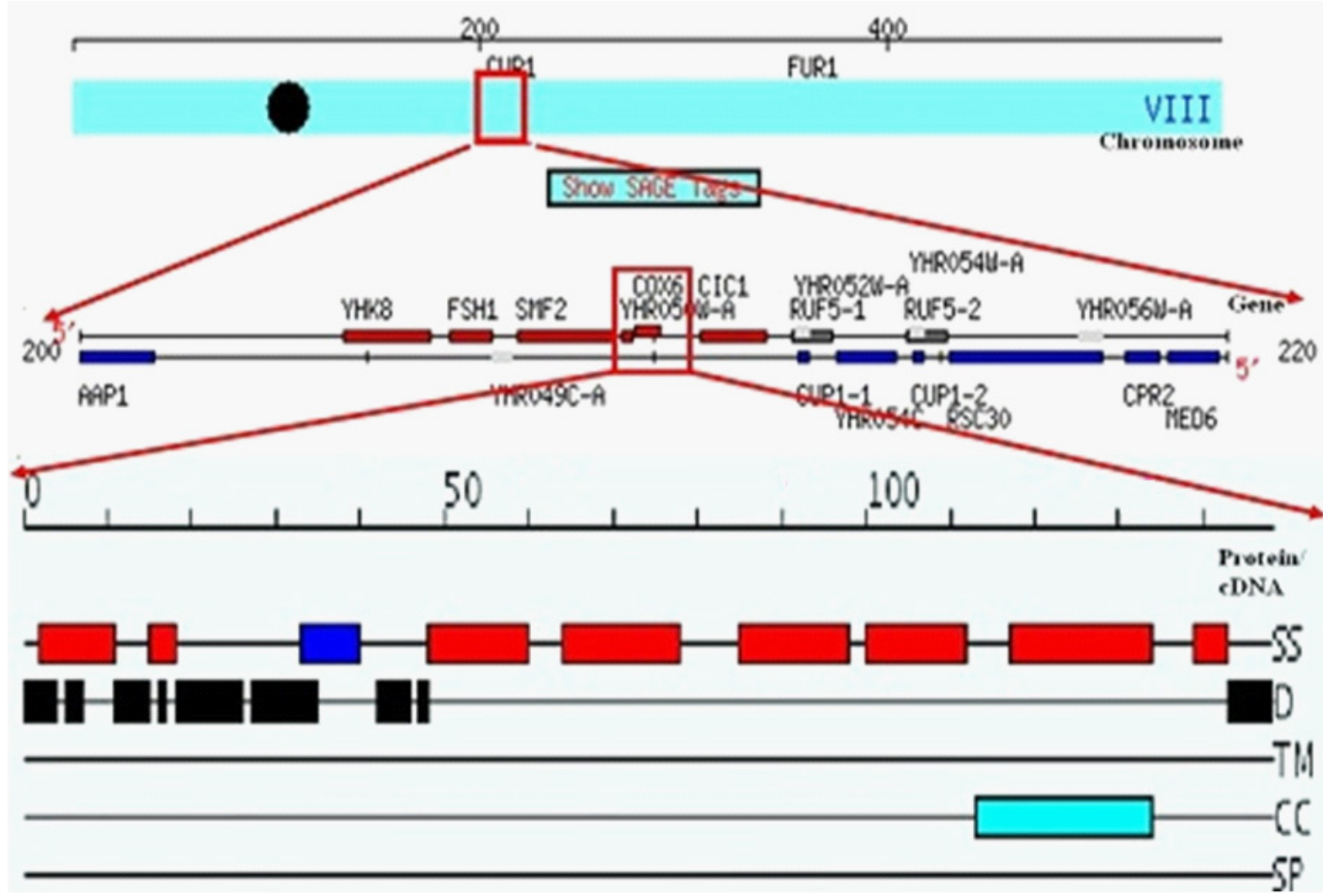

Supplementary Figure 4. Section A: Ideogram of the COX6 gene on chromosome VIII and a snapshot of predicted structural information about the protein/cDNA sequence. The approximate locations of point mutations, base substitutions, are marked by pink arrows. A legend on the right-hand side of the image indicates what data that section of the image is displaying. SS: Secondary Structure, D: Disordered Regions, TM: Transmembrane Regions, CC: Coiled Coil Regions and SP: Signal Peptide. Cited from Saccharomyces Genome Database, SGD, and Yeast Resource Center, YRC. 
Section B

Actttatatgttactggettactacgggcaaagaagtacacctctaatataacaattcttagactagtataagtatacatttatccaagaataa taacagaaaattccaatcaaaaagttggtgttaggctatactgatggecgtatcgctccatacgagccaatcagggccecgcgcgttattcc ggccttacagcttctttgaatctccctatgaaaagggacctaattggtccggtcaaagcattaataaagatcaacaattgctcttgcttatcaag gtgccagatctcaaggttacctcatttcttacatttcatccacatttagcacacttatttattattacaatttgaaaattgtatcacttctgagactt agtagcggagataaacagccgaacaattgtattgacacataaactcaataaatatacaaca atg tta tca agg gcc ata ttc aga aat cca gtt ata aat aga act tta ttg aga gec aga cct ggt gct tat cat gca act aga ttg act aaa aat acg tt att caa agt agg aag tat tct gac gca cat gat gaa gaa acc ttt gag gaa ttc acc gca aga tac gaa aag gag ttt gat gaa gec tat gat ttg $\mathrm{ttt}$ gaa gtg caa aga gtg ctc aac aac tgt ttt tcc tat gat tta gtt cct gct cct get gtt att gaa aaa gct ttg agg gct gccagaagagtcaatgacttacctaccgcaattagagtatttgaggctttgaatacaaggtggagaatgaagaccaatacaaggcctactt ggatgaattgaaggatgtcagacaagaattgggcgttcccttaaaggaagagctattccaagctcttct taataataaggaaaaagctac cacacaacgtctgtaatttgttgtccttttttatttgtggaaaattcctcaatttgaaataagattcgtatttatttgtaaaacgatttagttttatttttt tttttcttccetttaccttattattgtttaccetttatgggatattcatccacctcagaactaatatatcaaatcaacgt

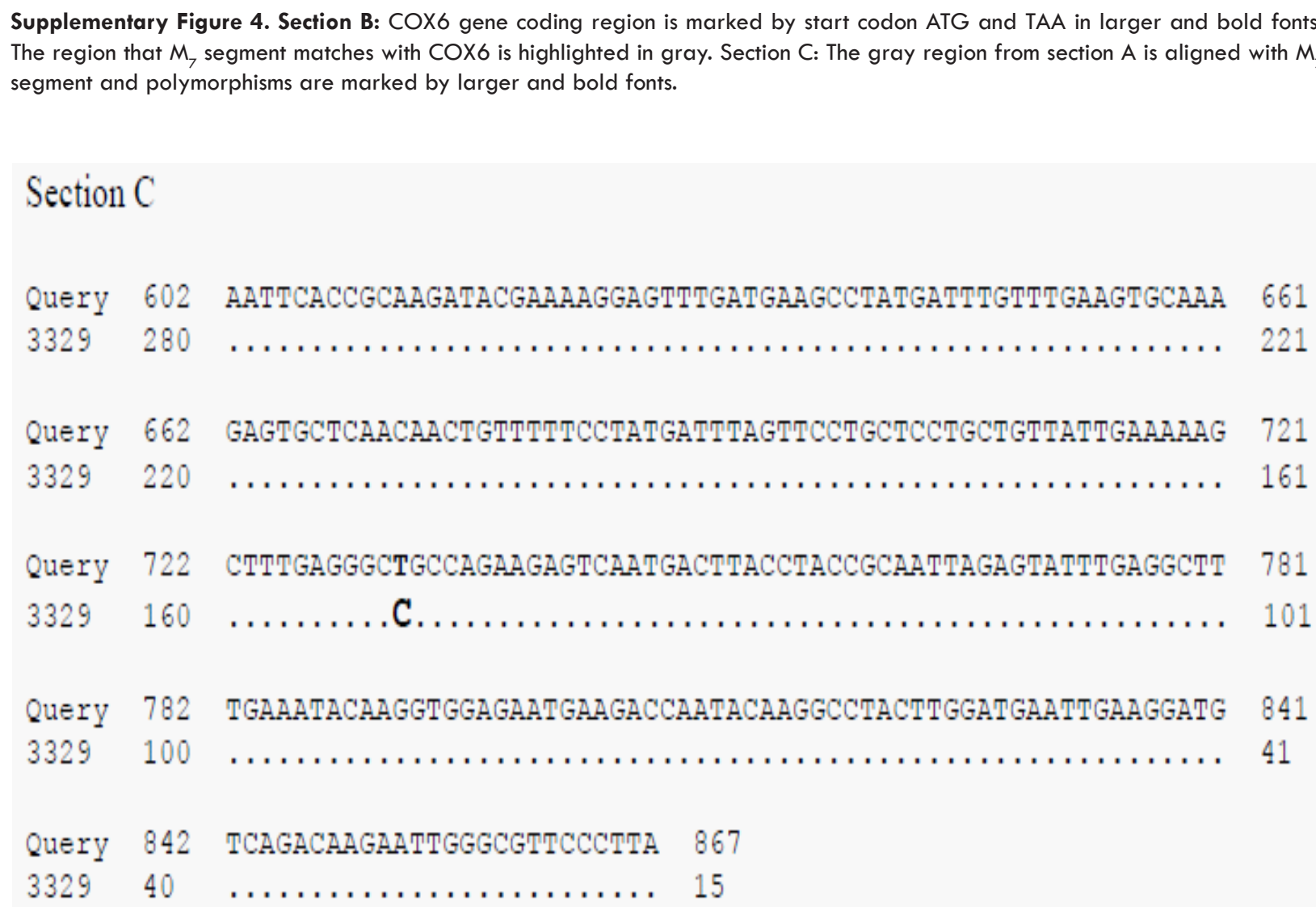

Supplementary Figure 4. Section C: The gray region from section A is aligned with $M_{7}$ segment and polymorphisms are marked by larger and bold fonts. 